\title{
Description of 29, COVID-19 Patients from District Nowshera, Pakistan
}

\author{
Hamzullah Khan* \\ Department of Hematology, Nowshera Medical College, Nowshera Pakistan
}

"Corresponding author: Hamzullah khan, Associate Professor, Department of Hematology, Nowshera Medical College, Nowshera, Pakistan, Tel: 03344802902; E-mail: hamzakmc@gmail.com

Received: 19 Apr, 2020 | Accepted: 25 Apr, 2020 | Published: 05 May, 2020

Citation: Khan H (2020) Description of 29, COVID-19 Patients from District Nowshera, Pakistan. J Emerg Dis Virol 5(1): dx.doi. org/10.16966/2473-1846.150

Copyright: (C) $2020 \mathrm{Khan} \mathrm{H}$. This is an open-access article distributed under the terms of the Creative Commons Attribution License, which permits unrestricted use, distribution, and reproduction in any medium, provided the original author and source are credited.

\begin{abstract}
Objectives: To know about the clinical presentation, demographic information, risk factors and outcome of COVID-19 in 29 COVID-19 positive patients of District Nowshera, Pakistan.

Material and Methods: A total of 29 COVID-19 positive patients were included and the relevant information was recorded on a pre-designed proforma prepared in accordance with the objectives of the study.

Results: Out of total 29 cases, 22 (76\%) were males and 7 (24\%) females. The Mean age with Standard deviation was $45 \pm 20.5$ years. The minimum age of COVID positive patient was 14 years with a maximum of 85 years with age range of 71 years. 5 (17.2\%) had co-morbidities. Out of total $8(27.6 \%)$ presented with cough, shortness of breath and flue, $6(20 \%)$ had only fever and cough while $12(41.4 \%)$ had no symptoms at time of presentation. Thirteen (44.8\%) had history of travel to an area with COVID-19 epidemics. $23(79.3 \%)$ had close contact history with COVID-19 positive patients. We observed 3/29 (10.34\%) mortality rate in positive cases and 4/29 (13.79\%) refractory positive cases with a male predominance.
\end{abstract}

Conclusion: Male gender, older age, history of travel to an epidemic area and contacts with positive COVID-19 patients are major risk factor for 2019nCoV positivity.

Keywords: COVID-19; Risk factor; Mortality; Refractory COVID-19

\section{Introduction}

Corona Virus disease (COVID-19) is caused by a virus called SARS-COV2 and is a potentially fatal disease with associated social stigma [1]. Extensive measures have been taken by the authorities to reduce its spread, person to person transmission to control the current epidemic.

According to the World Health Organization, the viral diseases are continue to emerge and are representing serious health issues in time and future. In 2002-03 world experienced outbreak of Sever Acute Respiratory Distress Syndrome (SARS) and H1N1 (Homophiles Influenza) in 2009, Middle East Respiratory Syndrome (MERS) in Saudi Arabia in 2012 and Corona Virus disease (COVID) in 2019 [2]. Case fatality rate of $2.3 \%$ has been reported from china that is lower than SARS (9.5\%), MERS (34.4\%) and H7N9 (39\%) [3].

In Pakistan the literature so for covering the prevalence and incidence is deficient and we found no published data, however the so for reported data from government sources declares 4000 confirmed cases with 54 deaths. Punjab is the province with highest number of corona cases reaching 2000 [4].
The battle against COVID-19 is still continuing across the globe in all affected countries. For that valued reason the people adherence to preventive and precautionary measures are essential, which largely depends on the knowledge attitude and practice of people toward COVID-19 in accordance with KAP theory [5].

Present study was therefore designed as to know about the clinical presentation, demographic information, risk factors and outcome of COVID-19 in 29 COVID-19 positive patients of District Nowshera.

\section{Methodology}

This descriptive cross sectional study was conducted from Feb 2020 to $19^{\text {th }}$ April, 2020 in COVID-19 clinic of QHAMC Nowshera and from district line list. A total of 29 COVID-19 cases were included in the study. All the confirmed cases of COVID-19 irrespective of age and gender were randomly included. Sample techniques were simple convenient probability sampling. All suspects, awaited and negative cases were excluded. Ethical endorsement was obtained from the institutional ethical review board of Nowshera Medical College hospital administration before the execution of the survey. Prior informed consent was obtained from all suspects and they were 
assured of confidentiality. All those suspect with COVOD Proforma score more than were subjected for testing their nasopharyngeal swabs for 2019-nCoV.

All samples were sent under strict observance of protocols to the Public health research laboratory of Khyber medical university Peshawar (a designated Lab for PCR of $2019 \mathrm{nCoV}$ by the Government of Khyber Pukhtunkhwa).

All those patients whose sample was collected were isolated mainly in the isolation unit of our hospital as well as quarantine designated by the Government or in other tehsil/district headquarter hospital of health/district administration to ensure to contain virus.

Results were received in 2-3 days, all with positive PCR report were isolated and kept under treatment, and their sample was repeated after 7 days of isolation/treatment.

Data was entered in SPSS $25^{\text {th }}$ version and descriptive and correlation statistics were applied. The frequency and proportion of numerical and categorical variables were presented in percentages.

\section{Results}

We totally screened 280 suspects in the COVID-19 clinic. Out of those 78 were selected for PCR testing based on a scoring criteria duly approved by the infections disease committee and administration.

Out of 78, 29 (37.17\%) were COVID-19 positive and 49 (62.82\%) were negative. We followed only the positive cases to know about their clinical presentation, exposure, risk factors and outcome of the disease criteria. The Mean age with Standard deviation was $45 \pm 20.5$ years. The minimum age of COVID positive patient was 14 years with a maximum of 85 years with age range of 71 years. $8 / 29(27.6 \%)$ had age more than 60 years of age (Table 1 ).

There were 22 (76\%) males and 7 (24\%) females. 19 (65.5\%) had a history of quarantine. 18 (62\%) were isolated in hospital for more than 10 days. Out to total 5 (17.2\%) had co-morbidities like coronary artery disease, asthma and heart failure, while $24(82.8 \%)$ had no associated complaints (Table 2).

Out of total $8(27.6 \%)$ presented with cough + shortness of breath and flue, 6 (20\%) had only fever and cough while $12(41.4 \%)$ had no symptoms at time of presentation. Sore throat, flue only and blood tinged sputum history was present in one patient each. 13 (44.8\%) had history of travel to an area with COVID-19 epidemics. 23 (79.3\%) had close contact history with COVID-19 positive patients (Table 3).

We observed $3 / 29(10.34 \%)$ mortality rate in positive cases and $4 / 29(13.79 \%)$ refractory positive cases with a male predominance (Table 4).

Table 1: Age Statistics.

\begin{tabular}{|c|c|c|}
\hline \multicolumn{3}{|c|}{ Age } \\
\hline \multirow{2}{*}{ Number } & Valid & 29 \\
\hline & Missing & 0 \\
\hline \multicolumn{2}{|l|}{ Mean } & 45 \\
\hline \multicolumn{2}{|l|}{ Median } & 42 \\
\hline \multicolumn{2}{|l|}{ Mode } & 32 \\
\hline \multicolumn{2}{|c|}{ Std. Deviation } & 20.5 \\
\hline \multicolumn{2}{|l|}{ Range } & 71 \\
\hline \multicolumn{2}{|c|}{ Minimum } & 14 \\
\hline \multicolumn{2}{|c|}{ Maximum } & 85 \\
\hline
\end{tabular}

Table 2: Descriptive statistics of gender, quarantine and co-morbidities.

\begin{tabular}{|l|l|}
\hline \multicolumn{2}{|c|}{ 1. Gender } \\
\hline Female & $7(24 \%)$ \\
\hline Male & $22(76 \%)$ \\
\hline Total & $29(100 \%)$ \\
\hline \multicolumn{2}{|c|}{ 2. Quarantine history } \\
\hline No & $10(34.5 \%)$ \\
\hline Yes & $19(65.5 \%)$ \\
\hline Total & $29(100 \%)$ \\
\hline & 3. Co-morbidities \\
\hline Asthma & $1(3.4 \%)$ \\
\hline CAD & $3(10.3 \%)$ \\
\hline CCF & $1(3.4 \%)$ \\
\hline No Co-Morbidities & $24(82.8 \%)$ \\
\hline Total & $29(100 \%)$ \\
\hline
\end{tabular}

Table 3: Descriptive statistics of clinical presentation, travel and contact history of COVID-19 patients.

\begin{tabular}{|l|c|}
\hline \multicolumn{2}{|c|}{ Symptoms } \\
\hline Cough with blood tinged sputum & Frequency \\
\hline Cough + SOB + Flue & $1(3.4 \%)$ \\
\hline Fever + Cough & $8(27.6 \%)$ \\
\hline Fever + Cough + Flue + Sneeze & $6(20.7 \%)$ \\
\hline Fever + Sore throat & $1(3.4 \%)$ \\
\hline No Symptoms & $1(3.4 \%)$ \\
\hline Total & $12(41.4 \%)$ \\
\hline & $29(100 \%)$ \\
\hline No & Travel \\
\hline Yes & $16(55.2 \%)$ \\
\hline Total & $13(44.8 \%)$ \\
\hline & $29(100 \%)$ \\
\hline No & \\
\hline Yes & \\
\hline Total & \\
\hline
\end{tabular}

\section{Discussion and Conclusion}

The outbreak in 2019 was totally different with presentation of pneumonia of unknown cause, later on the Chinese Centre for Disease Control and Prevention and local CDC attributed it to a novel virus belonging to corona family and was termed as 2019-nCoV [6].

We observed that The Mean age with Standard deviation was 45 \pm 20.5 years in our target population. The minimum age of COVID positive patient was 14 years with a maximum of 85 years with age range of 71 years. Similarly we observed a male dominance in present study.

Gender and age matters when there is talk about the prognosis and outcome of COVID-19. The New York time has reported that corona 
Table 4: Cross tabulation descriptive statistics of Gender vs. disease outcome and refractory COVID disease.

\begin{tabular}{|c|c|c|c|c|c|}
\hline \multicolumn{6}{|c|}{ Gender vs. Disease outcome } \\
\hline & & \multicolumn{4}{|c|}{ PT CONDITION } \\
\hline & & Died & \multicolumn{2}{|c|}{ Stable } & Total \\
\hline \multirow{2}{*}{ Gender } & Female & 1 & \multicolumn{2}{|r|}{6} & $7(24.13 \%$ \\
\hline & Male & 2 & \multicolumn{2}{|r|}{20} & $22(75.86 \%)$ \\
\hline \multicolumn{2}{|l|}{ Total } & $3(10.35 \%)$ & \multicolumn{2}{|c|}{$26(89.65 \%)$} & $29(100 \%)$ \\
\hline \multicolumn{6}{|c|}{ Gender vs. Refractory COVID-19 } \\
\hline & & \multicolumn{4}{|c|}{ Repeated Result } \\
\hline & & Not available & Negative & Positive & Total \\
\hline \multirow{2}{*}{ Gender } & Female & 5 & 2 & 0 & $7(24.13 \%$ \\
\hline & Male & 11 & 7 & 4 & $22(75.86 \%)$ \\
\hline \multicolumn{2}{|l|}{ Total } & $16(55.17 \%)$ & $9(31.3 \%)$ & $4(13.79 \%)$ & $29(100 \%)$ \\
\hline
\end{tabular}

virus is striking and felling more Italian males as compared to females in extreme of age because of their weak immunity status. They further elaborated that Italian model of mortality is a trend mirror of what they observed in China with more causality in male gender and at extreme age [6,7].

We observed that $8(27.6 \%)$ of the confirmed cases presented with cough + shortness of breath and flue, $6(20 \%)$ had only fever and cough while $12(41.4 \%)$ had no symptoms at time of presentation. Sore throat and simple flu were not common symptoms in our population. A study from china reported fever $(23,82.1 \%)$, dry cough $(22,81 \%)$ and dyspnoea $(14,50.0 \%)$ and lymphopaenia $(23,82.1 \%)$ in their study patients [8] that strongly coincides our findings.

It was observed that $13(44.8 \%)$ of the positive cases had history of travel to an area with COVID-19 epidemics. 23 (79.3\%) had close contact history with COVID-19 positive patients. Qiu H, et al. [9] reported from china that $(32,89 \%)$ COVID cases were reported from the contacts of family members of COVID-19 patients and (12,33\%) from suspects with history of exposure to epidemic areas. Anzai A, et al. [10] reported $30 \%$ cases from the travel history to an epidemic area in the last 14 days.

We observed $3 / 29(10.34 \%)$ mortality rate in positive cases. All of them were in the age more than 70 years and with associated comorbidities like coronary artery disease, and chest infection. The CDC reports 2019 shows that $53 \%$ of the COVID-19 infected patients that need ICU admission, and those $80 \%$ of the deaths were recorded in elderly people age $>65$ years, while no ICU admission or deaths were recorded in age less than 19 years of age.

Hence we concluded that male gender, older age, history of travel to an epidemic area and contacts with positive COVID-19 patients are major risk factor for $2019 \mathrm{nCoV}$ positivity. Similarly symptoms like fever, cough and shortness of breath are more commonly observed in COVID-19 patients as compared to sore throat, flue or fever alone.

It is further suggested that all health workers should understand the basics of $2019 \mathrm{nCoV}$, its clinical presentation and precautionary measures to contain virus and to avoid its spread in general community.

\section{Acknowledgements}

- Dr Mohammad Arif- Hospital Director, Qazi Hussain Ahmed Medical Complex Nowshera.

- Dr Mian Mohammad Naveed-Focal person COVID-19, Mian Rashid Husssain Shaheed Memorial Hospital Nowshera.

- Dr Abu Zar, Focal person COVID-19 District Nowshera, District Health Office, Nowshera.

- Dr Mohammad Zahid Khan Deputy Medical Superintendent, Focal Person COVID-19, Qazi Hussain Ahmed Medical Complex Nowshera.

\section{References}

1. Rothan HA, Byrareddy SN (2020) The epidemiology and pathogenesis of coronavirus disease (COVID-19) outbreak. J Autoimmun 109: 102433.

2. World Health Organization (2020) 2019-nCoV outbreak is an emergency of international concern.

3. Munster VJ, Koopmans $M$, van Doremalen N, van Riel D, de Wit E (2020) A Novel Coronavirus Emerging in China-Key Questions for Impact Assessment. N Engl J Med 382: 692-694.

4. Coronavirus in Pakistan-Confirmed Cases (2020).

5. The Nation (2020) Pakistan-Confirmed Cases.

6. Cascella M, Rajnik M, Cuomo A, Dulebohn SC, Di Napoli R (2020) Features, Evaluation and Treatment Coronavirus (COVID-19). Treasure Island (FL): StatPearls Publishing.

7. Department of System Reform (2020) Notice on the issuance of a recent work plan for the prevention and control of pneumonia caused by new coronavirus infection: Work plan for recent prevention and control of pneumonia caused by new coronavirus. Pneumonia Mechanism.

8. Zhang L, Zhu F, Xie L, Wang C, Wang J, et al. (2020) Clinical characteristics of COVID-19-infected cancer patients: A retrospective case study in three hospitals within Wuhan, China. Ann Oncol.

9. Qiu H, Wu J, Hong L, Luo Y, Song Q, et al. (2020) Clinical and epidemiological features of 36 children with coronavirus disease 2019 (COVID). Lancet Infect Dis S1473-3099: 30198-30195.

10. Anzai A, Kobayashi T, Linton NM, Kinoshita R, Hayashi K, et al. (2020) Assessing the Impact of Reduced Travel on Exportation Dynamics of Novel Coronavirus Infection (COVID-19). J Clin Med 9: 601. 